\title{
Neutron Diffraction Studies of the Magnetic Oxide Materials
}

\author{
J.B. Yang ${ }^{1}$, Q. Cai ${ }^{2}$, H.L. Du ${ }^{1}$, X.D. Zhou ${ }^{2}$, W.B. Yelon ${ }^{2}$ and W.J. James ${ }^{2}$ \\ ${ }^{1}$ School of Physics, Peking University \\ ${ }^{2}$ Materials Research Center, Missouri University of Science and Technology \\ 1P.R. China \\ 2USA
}

\section{Introduction}

Neutron diffraction (ND) is an extremely valuable tool for the investigation of magnetic materials, because of its ability to directly observe periodic magnetic structures, determine magnetic moment directions and magnitudes, to observe light elements $(\mathrm{H}, \mathrm{C}, \mathrm{N}, \mathrm{O}, \mathrm{F}$ etc.) that are otherwise difficult to locate from $\mathrm{x}$-ray diffraction due to the strong scattering of heavy elements, or to distinguish nearby elements in the periodic chart. Neutron diffraction has proven to be a very useful technique in the study of the magnetic oxides such as perovskites and transition metal oxides.

The perovskite-type $\mathrm{ABO}_{3}(\mathrm{~A}=\mathrm{La}, \mathrm{Sr}, \mathrm{B}=\mathrm{Fe}, \mathrm{Co}, \mathrm{Ni}, \mathrm{Cu}, \mathrm{Mn}, \mathrm{Ti})$ perovskites has attracted much attention due to their mixed electronic and oxygen ion conductivity, which shows potential to serve as oxygen separation membranes, oxygen sensors, and solid oxide fuel cell (SOFC), which results from the large number of oxygen vacancies (Kamata et al, 1978, Mizusaki et al., 1991, Kuo et al, 1989.) It is recognized that the physical properties of $\mathrm{ABO}_{3}$ are largely dependent on the oxygen deficiency (Goodenough, 1955, Srilomsak et al., 1989) . The mixed conductivity can be enhanced through the substitution of $\mathrm{La}^{3+} \mathrm{by} \mathrm{Sr}^{2+}$ at A sites, and the substitution of $\mathrm{Fe}^{3+}$ by other transition metal ions at $\mathrm{B}$ sites. The charge imbalance and overall charge neutrality can be maintained by the presence of charged oxygen vacancies and mixed valence state ions at the $B$ sites. These point defects are the origin of the mixed electronic and oxygen ion conductivity.

A three-dimensional framework made up of $\mathrm{BO}_{6}$ octahedra characterizes the $\mathrm{ABO}_{3}$ perovskite crystal structure. The interstices of this framework are sites for the large A cations, and the small $\mathrm{B}$ cations are at the centers of the octahedra. Every two neighboring $\mathrm{BO}_{6}$ octahedra share a common $\mathrm{O}$ atom. The perovskite structure is often stable with both divalent ( $\mathrm{Sr}, \mathrm{Ba}, \mathrm{Ca}$, etc.) and trivalent (e.g. lanthanide) A site occupation, and the charge imbalance and overall charge neutrality will be maintained by the formation of electrons, holes and/or charged oxygen vacancies. These point defects can take part in the electronic and/or oxygen ion conductivity, and this gives the material scientist an opportunity to alter the transport properties of a given oxide.

When perovskite materials that contain transition metal ions at the B sites are heated to sufficiently high temperature, they can equilibrate with the ambient oxygen by oxygen 
exchange. If the oxygen activities at the two sides of the perovskite are different, the oxygen ions can be transported from the high oxygen activity side to the low one. Therefore perovskites can be used as oxygen separation membranes or electrodes of SOFCs.

Strontium-doped lanthanum manganate is most commonly used as the cathode of SOFCs operated at high temperature. $\mathrm{LaMnO}_{3}$ is a p-type perovskite. At high temperature, it can have oxygen excess, stoichiometry, or oxygen deficiency, depending on the oxygen partial pressure.( Kamata et al, 1978, Mizusaki et al., 1991, Kuo et al, 1989.) For example, at $1200^{\circ} \mathrm{C}$, the oxygen content of $\mathrm{LaMnO}_{3}$ ranges from 3.079 to 2.947 under oxygen partial pressures of 1 to 10-11 atmosphere pressure.(Kamata et al, 1978) In addition to oxygen nonstoichiometry, $\mathrm{LaMnO}_{3}$ can also have La deficiency or excess. $\mathrm{LaMnO}_{3}$ with La excess may contain $\mathrm{La}_{2} \mathrm{O}_{3}$ as a second phase, and therefore $\mathrm{LaMnO}_{3}$ with La deficiency is recommended for use in SOFCs.

In recent years, work has focused on SOFCs that can operate at an intermediate temperature (IT) range $\left(600-800^{\circ} \mathrm{C}\right)$. In this temperature range, the metal alloy, such as stainless steel, which is cheap and easily fabricated, can be used as the interconnect, and the reliability of SOFCs is thus improved. In order for a SOFC to be operated in the IT range, the electrode kinetics have to be at least as fast as those occurring at high temperature. LSM, the current cathode material, is not suitable for use below $800^{\circ} \mathrm{C}$ due to its very low oxygen vacancy concentration. Therefore, research has to be done to find new material for use as the cathode of SOFCs operating in the IT range. In general, most cathodes have relied on the B-site cation, and doping on both A-sites and B-sites to improve electrical conductivity and catalytic performance. One approach to finding a new cathode material is to replace the $\mathrm{Mn}$ by other transition metals, such as $\mathrm{Fe}, \mathrm{Co}$, and $\mathrm{Ni}$ etc.

The strontium-doped lanthanum ferrite $\mathrm{La}_{1-x} \mathrm{Sr}_{x} \mathrm{FeO}_{3-\delta}$ (LSFO) has been intensively studied since it has good mixed conductivity at high temperature, and, thus, can be used as an oxygen membrane and is a candidate for the cathode of the SOFC. Undoped $\mathrm{LaFeO}_{3}$ has a low electrical conductivity and oxygen vacancy concentration, but the electrical conductivity and oxygen vacancy concentration are increased by the substitution of La by Sr. M. V. Patrakeev et al., 2003 studied the electron / hole and ion transport in LSFO in the oxygen partial pressure range of $10^{-19}-0.5 \mathrm{~atm}$ and temperatures between $750-950^{\circ} \mathrm{C}$, and found that the electronic and ionic conductivity increase with $\mathrm{Sr}$ content and attain maximal values at $x=0.5$. The conductivity can be explained by electron hopping between $\mathrm{Fe}^{3+}$ and $\mathrm{Fe}^{4+}$ in the high $\mathrm{P}_{\mathrm{O} 2}$ range and between $\mathrm{Fe}^{3+}$ and the $\mathrm{Fe}^{2+}$ in the low $\mathrm{P}_{\mathrm{O} 2}$ range. The LSFO material is stable when the $\mathrm{P}_{\mathrm{O} 2}>10^{-16} \mathrm{~atm}$ at $950^{\circ} \mathrm{C}$; oxygen vacancies will appear at $600-800^{\circ} \mathrm{C}$ in air. LSFO has shown excellent cathode performance at $750^{\circ} \mathrm{C}$ (Sun et al., 2005).

It is important to measure the oxygen vacancy concentration in LSFO. It is well known that neutron powder diffraction coupled with Rietveld refinement(Rodriguez-Carvajal 1998) can be used to determine the oxygen vacancy concentration in many oxides, since the sensitivity of neutron scattering to oxygen is comparable to other atoms. However, the precision of such a determination is unknown, especially at low vacancy content. In addition, neutron diffraction is a very sensitive direct probe of the magnetic moment, and LSFO exhibits magnetic ordering. If the magnetic moment of $\mathrm{Fe}$ is sensitive to the oxygen vacancy concentration, it can be used as an indirect probe of the oxygen vacancy concentration. To understand the physical properties of $\mathrm{La}_{0.6} \mathrm{Sr}_{0.4} \mathrm{FeO}_{3-\delta}$ and its behavior in SOFC and to be able to optimize its behavior, it is important to have a good knowledge of the defect chemistry of $\mathrm{La}_{0.6} \mathrm{Sr}_{0.4} \mathrm{FeO}_{3}$. In the present paper, samples of $\mathrm{La}_{0.6} \mathrm{Sr}_{0.4} \mathrm{FeO}_{3}$ with different amounts of 
oxygen vacancies were prepared by heating the samples in $\mathrm{N}_{2}, \mathrm{O}_{2}$, and $\mathrm{CO} / \mathrm{CO}_{2}$ mixtures. The effect of oxygen vacancies on the structural, magnetic and electronic properties was determined using neutron diffraction, magnetic measurements and Mössbauer spectra. It was found that magnetic ordering, charge disproportionation and charge ordering in these compounds shows strong dependence on the oxygen vacancies. The oxygen vacancies will changes the $\mathrm{Fe}$ valence states, the unit cell volume and the $\mathrm{Fe}-\mathrm{O}-\mathrm{Fe}$ bond angle. These dramatically affect the Fe-O-Fe superexchange coupling. Therefore by creating oxygen vacancies or having excess oxygen, the exchange interaction of $\mathrm{Fe}-\mathrm{O}$ and the valence state of Fe ions are affected, and lead to large changes in the magnetic and transport properties, such as the magnetic ordering temperature, the magnetic moments, the hyperfine interactions and electric conductivity in the pervoskite structure.

\section{Experimental methods}

The liquid-mixing method (Eror et al., 1986) was used to synthesize fine LSFO powder. An aqueous solution of Fe nitrate was first prepared and thermogravimetrically standardized. The lanthanum carbonate, and strontium carbonate were added to form a clear solution. Citric acid and ethylene glycol were added to the nitrate solution and then heated slowly to form a polymeric precursor, which was heated to $250^{\circ} \mathrm{C}$ to form an amorphous resin. This resin was calcined at $800^{\circ} \mathrm{C}$ for 8 hours. The powders were pressed at $207 \mathrm{MPa}$ to form a dense bar. The bar was sintered at $1000-1200^{\circ} \mathrm{C}$ for $24 \mathrm{~h}$ under different environments( air, $\mathrm{N}_{2}, \mathrm{O}_{2}$ or $\mathrm{CO} / \mathrm{CO}_{2}$ ), followed by quenching to room temperature. We assume the oxygen nonstoichiometry of the quenched samples is the same as before quenching. The magnetization curves of the samples were measured using a superconducting quantum interference device SQUID magnetometer in a field of up to $6 \mathrm{~T}$ from $1.5 \mathrm{~K}$ to $800 \mathrm{~K}$. A magnetic field of 50 Oe was used for the field cooling(FC) and zero field cooling(ZFC) process. The crystal phase was identified by x-ray diffraction analysis using $\mathrm{Cu} \mathrm{Ka}$ radiation. The powder neutron diffraction experiments were performed at the University of MissouriColumbia research reactor using neutrons of wavelength $1.4875 \AA$. The data for each sample were collected over $24 \mathrm{~h}$ In order to study the oxygen stoichiometry change in air at high temperature, in-situ neutron diffraction studies were carried out at high temperature (up to $800^{\circ} \mathrm{C}$ ) for the samples unquenched and quenched at $1500^{\circ} \mathrm{C}$ in air. The Rietveld method was used to refine the data by using the FULLPROF code (Rodriguez-Carvajal 2000), in which the magnetic ordering was modeled by a separate phase.

\subsection{Results and discussion}

\subsubsection{The effect of heat treatment under different gas environments}

Figure 1 shows the typical ND patterns of $\mathrm{La}_{0.6} \mathrm{Sr}_{0.4} \mathrm{FeO}_{3}$ powders at different heat treatment conditions. Similar patterns are observed for all samples, showing them to be single phase. The symmetry of the samples remains rhombohedral (space group $R^{-} 3 c$ ) throughout the series. A cubic structure (space group $\mathrm{Pm}^{-} 3 \mathrm{~m}$ ) was also proposed for these compounds, but it was found that the data could be better fitted in a hexagonal structure (space group $R^{-} 3 c$ ) as confirmed by the following neutron diffraction data refinement. The model is a rhombohedral structure with space group $\mathrm{R} \overline{3} \mathrm{c}$. The lattice parameters (hexagonal setting) are $a=b \approx \sqrt{2} a_{p}, c \approx 2 \sqrt{3} a_{p}, \alpha=\beta=90^{\circ}$, and $\gamma=120^{\circ}$, where $a_{p}$ is the lattice parameter of 


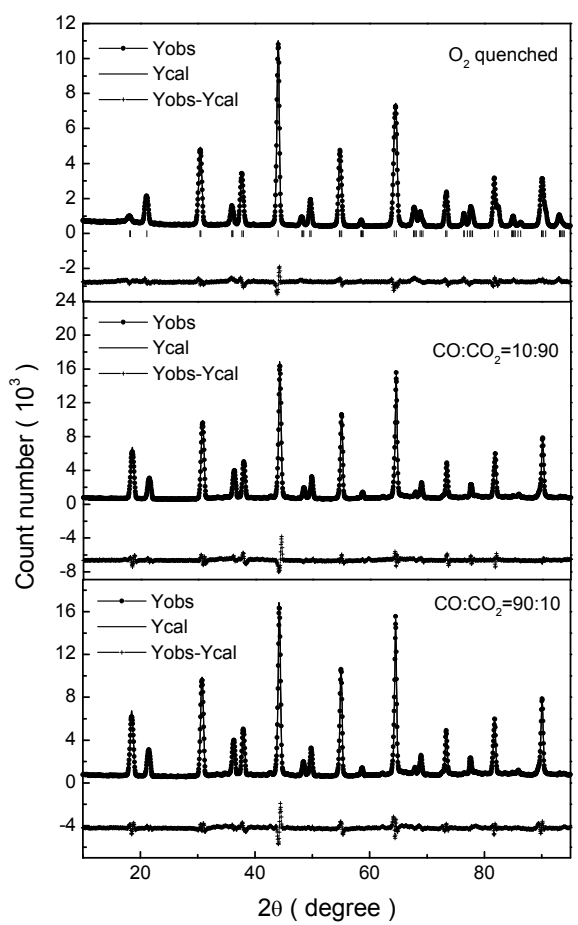

Fig. 1. Neutron diffraction patterns of $\mathrm{La}_{0.6} \mathrm{Sr}_{0.4} \mathrm{FeO}_{3}$ quenched at $\mathrm{O}_{2}$ and $\mathrm{CO} / \mathrm{CO}_{2}$. atmospheres

the basic cubic perovskite cell. In this model, the large cations $\mathrm{La}^{3+} / \mathrm{Sr}^{2+}$ occupy the 6 a sites, the small cations $\mathrm{Fe}^{3+} / \mathrm{Fe}^{4+}$ occupy the $6 \mathrm{~b}$ sites, and the oxygen ions occupy the 18e sites. The magnetic structure is modeled as having antiferromagnetic ordering with the moments in the hexagonal plane, which reverse between the positions $(0,0,0)$ and $(0,0,1 / 2)$. The magnetic model has the symmetry $\mathrm{R} \overline{3}$, and the magnetic moments on the two sites are constrained to be equal. It is difficult to use XRD patterns to determine the structural distortion, and the oxygen vacancy concentration. Accordingly, neutron diffraction was employed to distinguish the differences between the structures of the samples, and to determine the oxygen vacancy concentration.(Yang et al., 2002)

As evidenced from this figure, all samples crystallize in the rhombohedral structure with space group R-3c. The lattice parameters and bond angle are shown in Fig. 2(a) and (b). It can be seen that the unit cell volume increases when the $\mathrm{La}_{0.6} \mathrm{Sr}_{0.4} \mathrm{FeO}_{3}$ is quenching in the $\mathrm{CO} / \mathrm{CO}_{2}$ atmosphere. The unit cell volume of three $\mathrm{CO} / \mathrm{CO}_{2}$-reduced samples are larger by about $5 \AA^{3}$ than those of the $\mathrm{O}_{2-}$ and $\mathrm{N}_{2}$-quenched samples. The ratio of the lattice parameters a/c changes from 0.4113 for the $\mathrm{O}_{2}$-quenched sample to 0.40840 for the reduced samples, which decreases the distortion from cubicity. This change affects the peak positions and the sharpness of the diffraction peaks. The diffraction peak splitting for the $\mathrm{CO} / \mathrm{CO}_{2}$ treated samples is dramatically reduced compared to the $\mathrm{O}_{2}$-treated samples. The first diffraction peak is much stronger in the reduced samples than in the $\mathrm{O}_{2}$-quenched samples. 
This peak proves to be purely magnetic and the change reflects a large increase in magnetic moments for the $\mathrm{CO} / \mathrm{CO}_{2}$-reduced samples. An antiferromagnetic structure has been confirmed for all samples. Fe atoms at $(0,0,0)$ couple antiferromagnetically with those at $(0,0,1 / 2)$ along the c-axis. The Fe atoms show a magnetic moment $3.8 \mu_{\mathrm{B}}$ in the $\mathrm{CO} / \mathrm{CO}_{2-}$ treated $\mathrm{La}_{0.6} \mathrm{Sr}_{0.4} \mathrm{FeO}_{3}$ as compared to $1.2 \mu_{\mathrm{B}}$ in the $\mathrm{O}_{2}$-treated samples at $290 \mathrm{~K}$. The extent of oxygen vacancy in these compounds has been obtained by refinements of neutron diffraction data. The $\mathrm{O}_{2^{-}}$, and $\mathrm{N}_{2}$-quenched samples show similar patterns, and there are less than $1 \%$ vacancies on the oxygen sites. The oxygen vacancy concentration is around $7-10 \%$ for the samples quenched in the $\mathrm{CO} / \mathrm{CO}_{2}$ mixtures. It is noticed that these values are about $2 \%$ less than those measured from the iodometric method. This difference might cause from the systematic errors of the two techniques.
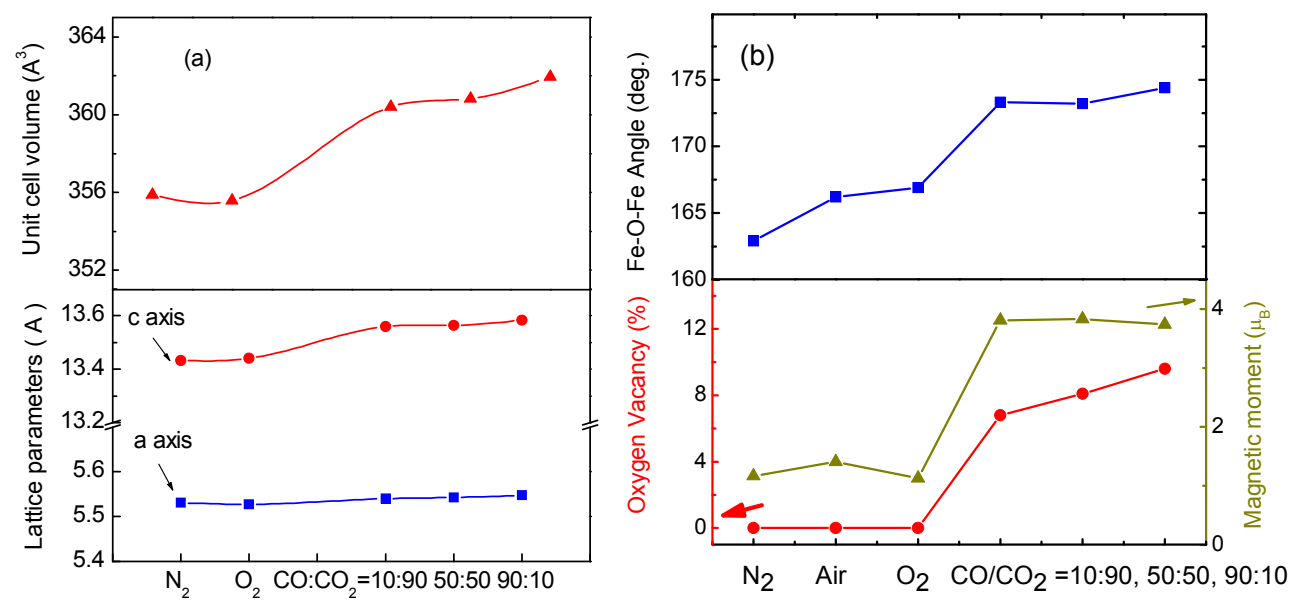

Fig. 2. The lattice parameters and unit cell volumes of $\mathrm{La}_{0.6} \mathrm{Sr}_{0.4} \mathrm{FeO}_{3}$ treated at different gases(a), the bond angle, oxygen vacancy and magnetic moments of $\mathrm{La}_{0.6} \mathrm{Sr}_{0.4} \mathrm{FeO}_{3}$ treated at different gases $(b)$

The typical neutron patterns of the samples $\left(\mathrm{N}_{2}, \mathrm{O}_{2}\right.$, and $\left.50 \% \mathrm{CO} / 50 \% \mathrm{CO}_{2}\right)$ at $290 \mathrm{~K}$ were collected (data not shown here). The $\mathrm{N}_{2}$-treated sample shows a rhombohedral structure and are refined in the space group $R \overline{3} \mathrm{c}$. The diffraction peak half width for the $\mathrm{CO} / \mathrm{CO} 2$ treated samples is dramatically reduced compared to the $\mathrm{N}_{2}$-treated samples which is similar to the XRD patterns. The rhombohedral splitting of the peaks is not too obvious for the $\mathrm{CO} / \mathrm{CO}_{2}-$ treated samples. Thus, we have used both a cubic cell space group $\operatorname{Pm} \overline{3} m$ and a rhombohedral cell, space group $R \overline{3} c$ to refine the structure. The rhombohedral structure gives much better refinement results. For example, $\chi^{2}$ is 7.56 for the refinement using space group $R \overline{3} c$ and 15.8 for space group $P m \overline{3} m$ for the $N_{2}$-treated sample. Therefore, all samples have been refined with a rhombohedral cell space group $R \overline{3} c$ ). The first diffraction peak [101] at about $19^{\circ}$ ) is much stronger in the reduced samples than in the air-, $\mathrm{N}_{2-}$, and $\mathrm{O}_{2}$-quenched samples. This peak proves to be purely magnetic and the change reflects a large increase in magnetic moments for the $\mathrm{CO} / \mathrm{CO}_{2}$-reduced samples. The air-, $\mathrm{O}_{2^{-}}$, and $\mathrm{N}_{2^{-}}$ quenched samples show similar patterns, and there is less than $1 \%$. The ${ }^{57 F e}$ Mössbauer 
spectra of $\mathrm{La}_{0.6} \mathrm{Sr}_{0 .} 4 \mathrm{FeO}_{3-\delta}$ treated in $\mathrm{N}_{2}$ measured at different temperatures are shown in Fig. 3 (a). The hyperfine parameters are listed in Table. I. The Mössbauer spectroscopy of $\mathrm{N}_{2}$ at room temperature shows a paramagnetic behavior. Two singlets were used in the fitting for the spectrum. The isomer shifts are $0.26 \mathrm{~mm} / \mathrm{s}$ and $0.18 \mathrm{~mm} / \mathrm{s}$, which are exactly what would be expected for the $\mathrm{Fe}^{3+}$ and $\mathrm{Fe}^{4+}$ ions. The ratio of $\mathrm{Fe}^{3+} / \mathrm{Fe}^{4+}$ is $63.9 / 36.1$, corresponding to an oxygen vacancy, $\delta=0.023$. At $130 \mathrm{~K}$ and $20 \mathrm{~K}$, the spectra are comprised of three superimposed magnetic hyperfine patterns.
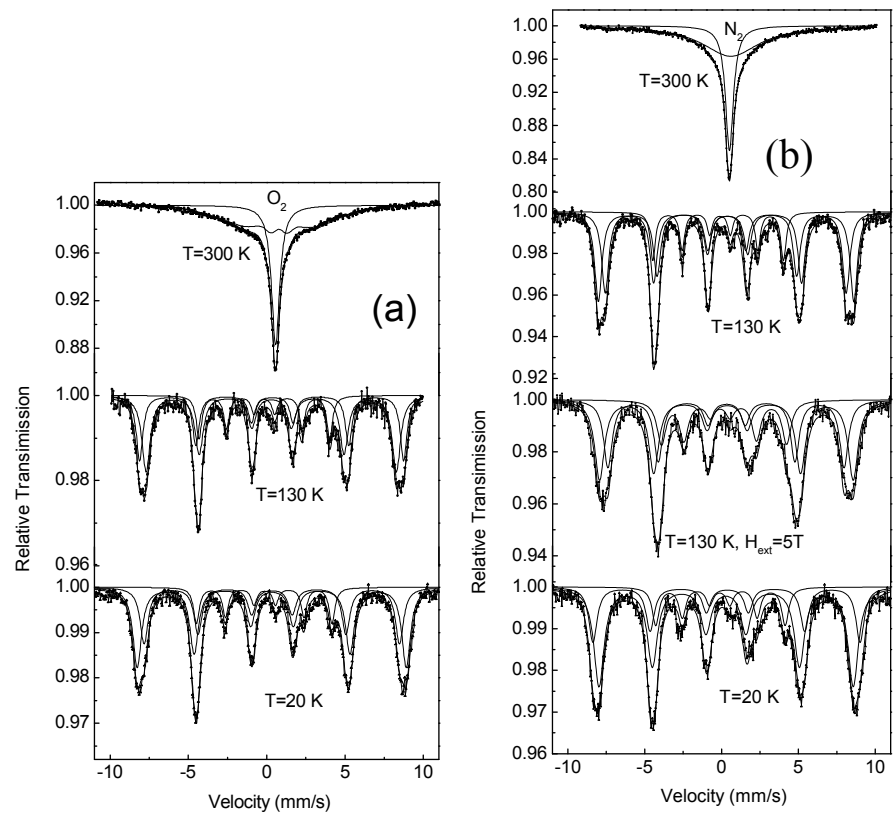

Fig. 3. ${ }^{57} \mathrm{Fe}$ Mössbauer spectra of $\mathrm{La}_{0.6} \mathrm{Sr}_{0.4} \mathrm{FeO}_{3-\delta}$ treated in $\mathrm{N}_{2}(\mathrm{a})$ and $\mathrm{O}_{2}(\mathrm{~b})$ measured at different temperatures

The parameters of these spectra are mostly applicable to the $\mathrm{Fe}^{3+}$ and $\mathrm{Fe}^{5+}$ valence states. These observations indicate a change from a paramagnetic $\mathrm{Fe}^{4+}$ state to a mixed valence state $\mathrm{Fe}^{3+} / \mathrm{Fe}^{5+}$ resulting from the charge disportortionation reaction, $2 \mathrm{Fe}^{4+} \Leftrightarrow \mathrm{Fe}^{3+}+\mathrm{Fe}^{5+}$ (Takano et al., 1997). Here it was assumed that the two subspectra with the larger hyperfine fields correspond to the $\mathrm{Fe}^{3+}$ ions, while the one with the lowest hyperfine field $(\sim 26 \mathrm{~T})$ corresponds to $\mathrm{Fe}^{5+}$ ions, which was used by Dann et al, 1994.

Similar spectra were observed for $\mathrm{O}_{2}$-quenched samples as shown in Fig. 3(b). At room temperature the rhombohedral relaxation of the hyperfine fields appears and therefore a Voigt peak-shaped sextet and a singlet were used in the fitting to account for the $\mathrm{Fe}^{3+}$ and $\mathrm{Fe}^{4+}$ ions. At low temperature, the charge disportortionation also takes place. The oxygen deficiency obtained from the relative areas of the Mössbauer spectra of the $\mathrm{Fe}^{3+}$ and $\mathrm{Fe}^{4+}$ ions in $\mathrm{O}_{2}$-treated sample is nearly zero, which agrees well with the neutron diffraction measurements. The Mössbauer spectra of the $\mathrm{CO} / \mathrm{CO}_{2}$-quenched samples are shown in Fig. 4. They show a typical sextet due to the antiferromagnetic coupling of the Fe atoms, which is 


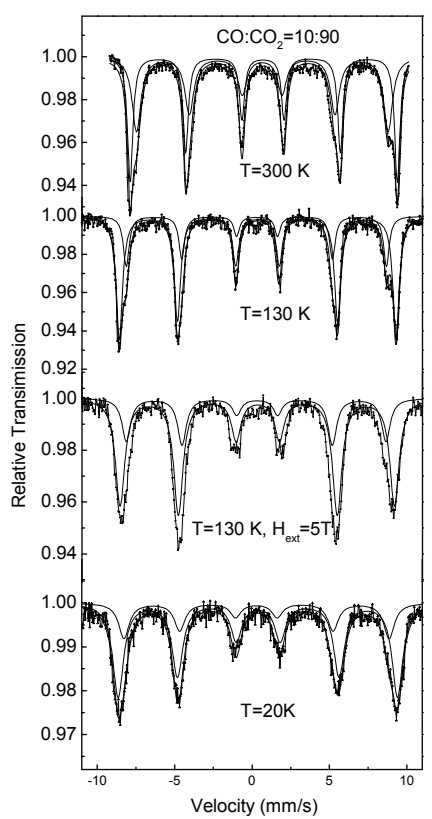

Fig. 4. The Mössbauer spectra of the $\mathrm{CO} / \mathrm{CO}_{2}$-quenched samples at different temperatures

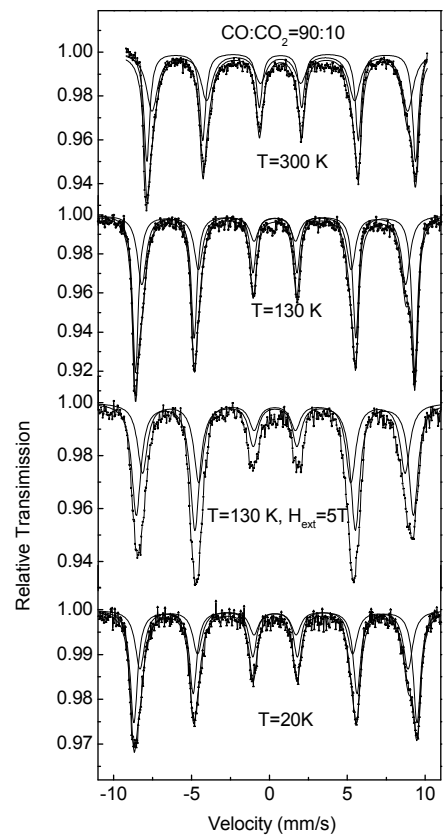

Fig. 5. Mössbauer spectra of the $\mathrm{CO} / \mathrm{CO}_{2}$-quenched $\mathrm{La}_{0.6} \mathrm{Sr}_{0.4} \mathrm{FeO}_{3}$ samples measured at different temperatures 


\begin{tabular}{|c|c|c|c|c|c|}
\hline & & IS $(\mathrm{mm} / \mathrm{s})$ & $\mathrm{QS}(\mathrm{mm} / \mathrm{s})$ & $\mathrm{B}_{\mathrm{hf}}(\mathrm{kOe})$ & Int.(\%) \\
\hline & \multicolumn{5}{|c|}{$\mathrm{N}_{2}$-quenched } \\
\hline \multirow{3}{*}{$20 \mathrm{~K}$} & $\mathrm{Fe}^{3+}$ & 0.442 & -.058 & 540.9 & 26.3 \\
\hline & $\mathrm{Fe}^{3+}$ & 0.381 & .001 & 515.0 & 58.4 \\
\hline & $\mathrm{Fe}^{5+}$ & -0.005 & 0.047 & 262.3 & 15.3 \\
\hline \multirow{3}{*}{$130 \mathrm{~K}$} & $\mathrm{Fe}^{3+}$ & 0.420 & -.106 & 517.0 & 43.9 \\
\hline & $\mathrm{Fe}^{3+}$ & 0.386 & -.077 & 488.9 & 39.3 \\
\hline & $\mathrm{Fe}^{5+}$ & -0.085 & -0.118 & 264.2 & 16.8 \\
\hline \multirow{3}{*}{$\begin{array}{l}130 \mathrm{~K} \\
(\mathrm{H}=5 \mathrm{~T})\end{array}$} & $\mathrm{Fe}^{3+}$ & 0.415 & -.051 & 513.3 & 44.9 \\
\hline & $\mathrm{Fe}^{3+}$ & 0.387 & -.039 & 478.0 & 33.2 \\
\hline & $\mathrm{Fe}^{5+}$ & -0.033 & 0.251 & 253.4 & 21.9 \\
\hline \multirow[t]{3}{*}{ RT } & $\mathrm{Fe}^{3+}$ & 0.261 & - & - & 63.9 \\
\hline & $\mathrm{Fe}^{4+}$ & 0.180 & - & - & 36.1 \\
\hline & \multicolumn{5}{|c|}{$\mathrm{O}_{2}$-quenched } \\
\hline \multirow{3}{*}{$20 \mathrm{~K}$} & $\mathrm{Fe}^{3+}$ & 0.422 & -0.023 & 534.3 & 51.2 \\
\hline & $\mathrm{Fe}^{3+}$ & 0.399 & -0.001 & 507.1 & 33.5 \\
\hline & $\mathrm{Fe}^{5+}$ & -0.053 & -0.034 & 268.9 & 15.3 \\
\hline \multirow{3}{*}{$130 \mathrm{~K}$} & $\mathrm{Fe}^{3+}$ & 0.427 & -0.046 & 524.6 & 33.2 \\
\hline & $\mathrm{Fe}^{3+}$ & 0.399 & -0.252 & 497.1 & 48.4 \\
\hline & $\mathrm{Fe}^{5+}$ & -0.058 & -0.015 & 259.6 & 18.4 \\
\hline \multirow[t]{3}{*}{ RT } & $\mathrm{Fe}^{3+}$ & 0.331 & 0.047 & 191.0 & 59.9 \\
\hline & $\mathrm{Fe}^{4+}$ & 0.202 & & & 40.1 \\
\hline & \multicolumn{5}{|c|}{$\mathrm{CO} / \mathrm{CO}_{2}=10: 90$} \\
\hline \multirow[t]{2}{*}{$20 \mathrm{~K}$} & $\mathrm{Fe}^{(3-x)+}$ & 0.479 & -0.026 & 561.6 & $73^{*}$ \\
\hline & $\mathrm{Fe}^{(3-x)^{+}}$ & 0.376 & 0.012 & 533.1 & $27^{*}$ \\
\hline \multirow[t]{2}{*}{$130 \mathrm{~K}$} & $\mathrm{Fe}^{(3-x)^{+}}$ & 0.442 & 0.014 & 555.8 & $73^{*}$ \\
\hline & $\mathrm{Fe}^{(3-x)^{+}}$ & 0.379 & -0.052 & 522.7 & $27^{*}$ \\
\hline \multirow{2}{*}{$\begin{array}{l}130 \mathrm{~K} \\
(\mathrm{H}=5 \mathrm{~T})\end{array}$} & $\mathrm{Fe}^{(3-\mathrm{x})^{+}}$ & 0.435 & -0.032 & 551.4 & $73^{*}$ \\
\hline & $\mathrm{Fe}^{(3-x)^{+}}$ & 0.375 & -0.068 & 521.6 & $27^{*}$ \\
\hline \multirow[t]{3}{*}{ RT } & $\mathrm{Fe}^{(3-x)^{+}}$ & 0.324 & 0.050 & 535.5 & $73^{*}$ \\
\hline & $\mathrm{Fe}^{(3-\mathrm{x})^{+}}$ & 0.236 & 0.020 & 501.1 & $27^{*}$ \\
\hline & \multicolumn{5}{|c|}{$\mathrm{CO} / \mathrm{CO}_{2}=90: 10$} \\
\hline \multirow[t]{2}{*}{$20 \mathrm{~K}$} & $\mathrm{Fe}^{(3-x)^{+}}$ & 0.469 & 0.024 & 565.5 & $60^{*}$ \\
\hline & $\mathrm{Fe}^{(3-x)^{+}}$ & 0.417 & -0.007 & 535.4 & $40^{*}$ \\
\hline \multirow[t]{2}{*}{$130 \mathrm{~K}$} & $\mathrm{Fe}^{(3-\mathrm{x})^{+}}$ & 0.439 & 0.009 & 557.4 & $60^{*}$ \\
\hline & $\mathrm{Fe}^{(3-x)^{+}}$ & 0.386 & -0.074 & 526.4 & $40^{*}$ \\
\hline \multirow{2}{*}{\begin{tabular}{|l|}
$130 \mathrm{~K}$ \\
$(\mathrm{H}=5 \mathrm{~T})$
\end{tabular}} & $\mathrm{Fe}^{(3-x)+}$ & 0.434 & -0.007 & 553.1 & $60^{*}$ \\
\hline & $\mathrm{Fe}^{(3-x)^{+}}$ & 0.388 & -0.055 & 524.1 & $40^{*}$ \\
\hline \multirow[t]{2}{*}{ RT } & $\mathrm{Fe}^{(3-x)^{+}}$ & 0.324 & 0.035 & 535.3 & $60^{*}$ \\
\hline & $\mathrm{Fe}^{(3-x)^{+}}$ & 0.272 & -0.063 & 504.1 & $40^{*}$ \\
\hline
\end{tabular}

Parameter constrained to the given value, and $0<x<1.0$.

Table 1. Hyperfine parameters of the $\mathrm{La}_{0.6} \mathrm{Sr}_{0.4} \mathrm{FeO}_{3}$ treated at different gases measured at different temperatures. 
confirmed by neutron diffraction and magnetic measurements. The best fitting can be reached by using two sextets for the fitting of the entire spectra by assuming two different Fe valence states. The average hyperfine field is 50-53 $\mathrm{T}$ at room temperature, which is of the same order as that of the Fe-oxide (such as $\mathrm{Fe}_{2} \mathrm{O}_{3}$ ). This large hyperfine field corresponds to a valence state between $\mathrm{Fe}^{2+}$ and $\mathrm{Fe}^{3+}$. There is no evidence in the spectra for the presence of any $\mathrm{Fe}^{5+}$ at low temperatures. An attempt to find evidence for the presence of distinct $\mathrm{Fe}^{4+}$ or $\mathrm{Fe}^{2+}$ lines in the spectra also failed. The two sextets have values of an isomer shift somewhere between $\mathrm{Fe}^{2+}$ and $\mathrm{Fe}^{3+}$ regions. The true oxidation state of $\mathrm{Fe}$ seems to be neither $\mathrm{Fe}^{2+}$ nor $\mathrm{Fe}^{3+}$ but an intermediate state (such as $\left.\mathrm{Fe}(3-x)^{+}, 0<x<1.0\right)$. Because the $\mathrm{CO} / \mathrm{CO}_{2-}$ treated samples have much higher oxygen vacancy concentrations, it suggests that some $\mathrm{Fe}^{4+}$ or even $\mathrm{Fe}^{3+}$ in the non-reduced samples are reduced to $\mathrm{Fe}^{(3-\mathrm{x})+}(0<\mathrm{x}<1.0)$, in order to maintain charge balance in these compounds. It is evident that the change of the Fe valence state from $\mathrm{Fe}^{4+}$ to $\mathrm{Fe}^{(3-x)+}$ results in a large hyperfine field and a large magnetic moment. The average quadrupole splitting of the $\mathrm{CO} / \mathrm{CO}_{2}$-quenched samples is smaller than that of the non-reduced sample, which indicates a decrease in the distortion from the cubic structure. This is consistent with the neutron diffraction data, which show a decrease of the distortion from cubic. It is found that the $\mathrm{CO} / \mathrm{CO}_{2}$-treated samples have the same a/c ratio (0.40855) as those $(\mathrm{a} / \mathrm{c}=0.40850)$ of $\mathrm{La}_{1-\mathrm{x}} \mathrm{Sr}_{\mathrm{x}} \mathrm{FeO}_{3-\delta}(\mathrm{x}=0.6$ and 0.7$)$, which is, near the boundary between the rhombohedral and cubic structures (Dann et al., 1994). The spectra measured under a magnetic field of $5 \mathrm{~T}$ at $130 \mathrm{~K}$ were also included in Figs. 3-5. As compared with the spectra at $130 \mathrm{~K}$ without the magnetic field, it is found that the intensities of the first and sixth line decrease. This indicates that there might be a canted magnetic moment in the magnetic sublattice, which implies that the antiferromagnetic structure is not perfect.

\subsubsection{The effect of quenching temperatures}

Figure 6 shows the typical ND patterns of $\mathrm{La}_{0.6} \mathrm{Sr}_{0.4} \mathrm{FeO}_{3}$ powders quenched at different temperatures in the air. The first peak at low angle is a pure magnetic peak; its intensity increases with the quenching temperature, and some of the split peaks merge into one peak when the quench temperature is high.

Figure 7 shows the change of lattice parameters $\mathrm{a}^{*}$ and $\mathrm{c}^{*}$ with the quenching temperature, in which $a^{*}$ represents $a / \sqrt{2}$ and $c^{*}$ represents $c / 2 \sqrt{3}$. The symmetry of L6SF quenched to room temperature from 700 to $1100^{\circ} \mathrm{C}$ remains rhombohedral, but the rhombohedral distortion becomes small when the quenching temperature is high. When the quenching temperature $\mathrm{T} \geq 1200^{\circ} \mathrm{C}$, the unit cell appears to be cubic. The presence of oxygen vacancies can relax the strain in the structure and reduce the distortion.

According to the direct refinement, the oxygen vacancy concentration increases from almost zero for the unquenched sample to about 0.2 for the $1500^{\circ} \mathrm{C}$ quenched sample. The statistical uncertainty shows that the direct refinement is reliable only when the oxygen vacancy concentration is high.

The unit cell volume increases as the quenching temperature increases by a total of $3.8 \AA^{3}$ from the unquenched sample to the $1500^{\circ} \mathrm{C}$ quenched sample. The statistical uncertainty in the unit cell volume is about $0.04 \AA^{3}$. It shows that, the unit cell volume can be a good metric for the determination of vacancy concentration. However, the unit cell volumes are relative 
due to the uncertainty in wavelength and sample position. Thus, the volumes of a series of samples can easily be compared, but the unit cell volume of a single specimen cannot be used to estimate its oxygen vacancy concentration. The small downturn in volume at the $1500^{\circ} \mathrm{C}$ quenched samples appears to be an artifact, since the data on the samples treated in different reducing atmospheres with vacancy concentration up to $9.6 \%$ show a continued increase in volume.

The unit cell expansion associated with the formation of oxygen vacancies can be explained by: a): The repulsive force arising between those mutually exposed cations when oxygen ions are absent in the lattice. $b$ ): The increase in cation size due to the reduction of Fe ions from a high valence state to a lower valence state, which must occur concurrently with the formation of oxygen vacancies in order to maintain electrical neutrality.

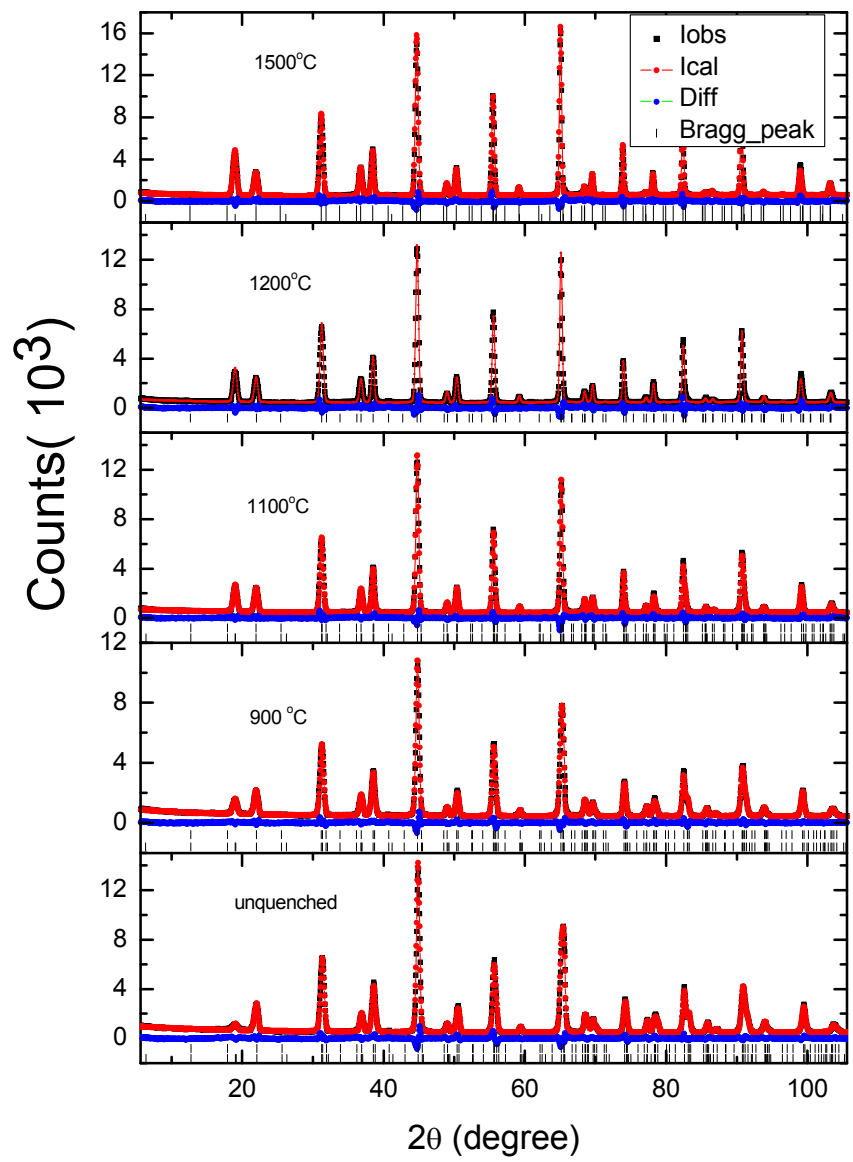

Fig. 6. The neutron diffraction patterns of unquenched, $900^{\circ} \mathrm{C}, 1100^{\circ} \mathrm{C}, 1200^{\circ} \mathrm{C}$, and $1500^{\circ} \mathrm{C}$ air quenched specimens. The black dots are the observed intensity, the solid red line is the calculated intensity, and their difference (blue) is under them. The upper tic marks show Bragg positions for the nuclear phase, and the lower ones are for the magnetic phase. 


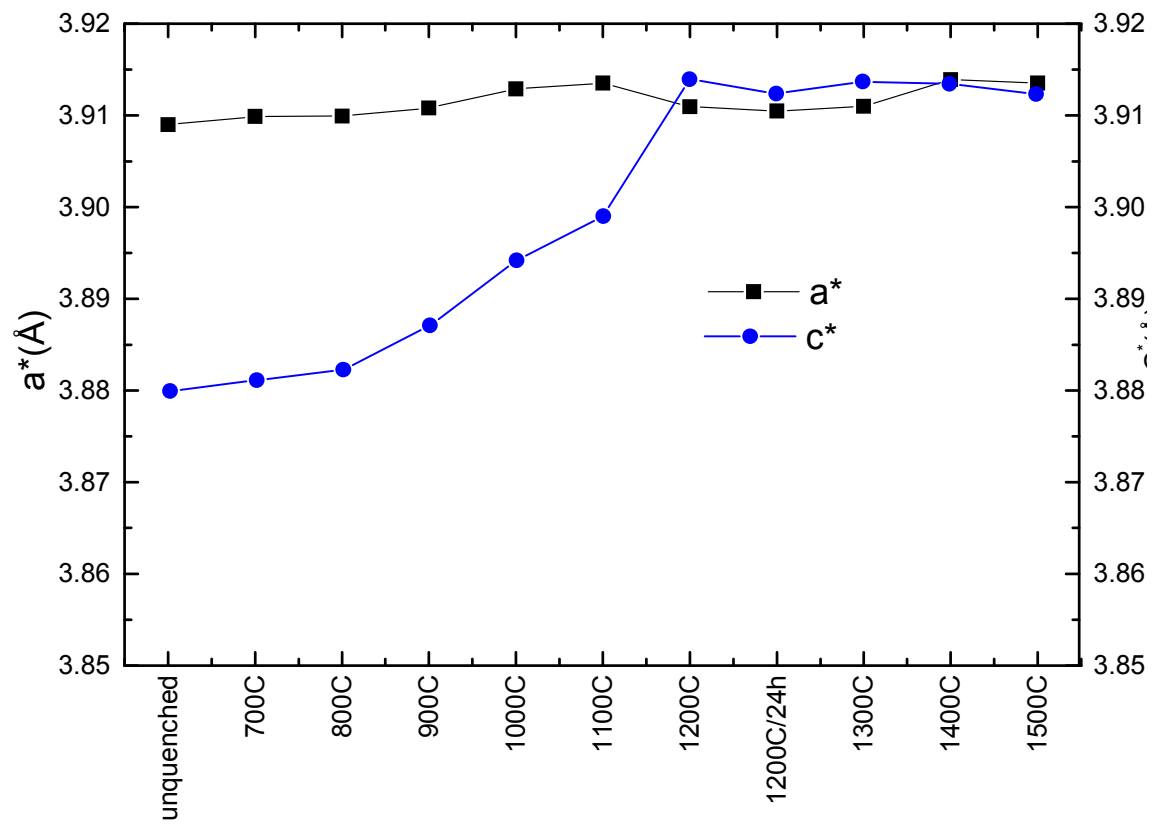

Fig. 7. Lattice parameters of $\mathrm{La}_{0.6} \mathrm{Sr}_{0.4} \mathrm{FeO}_{3}$ vs. quenching condition.

\begin{tabular}{|l|l|l|l|l|l|l|}
\hline $\begin{array}{l}\text { Quenching } \\
\text { Temperature }\end{array}$ & $\mathrm{a}(\AA)$ & $\mathrm{c}(\AA)$ & Vol. $\left(\AA^{3}\right)$ & Total O & $\begin{array}{l}\text { Mag.(RT) } \\
\left(\mu_{\mathrm{B}}\right)\end{array}$ & $\delta$ \\
\hline No Quench & $5.52818(17)$ & $13.44049(56)$ & $355.72(2)$ & $2.992(12)$ & $1.31(3)$ & $0.008(12)$ \\
\hline $700^{\circ} \mathrm{C}$ & $5.52942(15)$ & $13.44457(52)$ & $355.99(2)$ & $2.980(12)$ & $1.42(2)$ & $0.020(12)$ \\
\hline $800^{\circ} \mathrm{C}$ & $5.52946(15)$ & $13.44860(51)$ & $356.10(2)$ & $2.964(12)$ & $1.67(2)$ & $0.036(12)$ \\
\hline $900^{\circ} \mathrm{C}$ & $5.53072(16)$ & $13.46527(58)$ & $356.71(2)$ & $2.962(12)$ & $2.07(2)$ & $0.038(12)$ \\
\hline $1000^{\circ} \mathrm{C}$ & $5.53352(17)$ & $13.48996(65)$ & $357.72(2)$ & $2.936(16)$ & $2.44(2)$ & $0.064(16)$ \\
\hline $1100^{\circ} \mathrm{C}$ & $5.53456(16)$ & $13.50656(62)$ & $358.30(2)$ & $2.920(14)$ & $2.72(2)$ & $0.080(14)$ \\
\hline $1200^{\circ} \mathrm{C}$ & $5.53091(41)$ & $13.55839(190)$ & $359.20(6)$ & $2.872(18)$ & $2.98(2)$ & $0.128(18)$ \\
\hline $1200^{\circ} \mathrm{C} / 24 \mathrm{~h}$ & $5.53026(40)$ & $13.55285(191)$ & $358.97(6)$ & $2.856(14)$ & $3.07(2)$ & $0.144(14)$ \\
\hline $1300^{\circ} \mathrm{C}$ & $5.53098(25)$ & $13.55746(110)$ & $359.18(4)$ & $2.830(16)$ & $3.26(2)$ & $0.170(16)$ \\
\hline $1400^{\circ} \mathrm{C}$ & $5.53510(29)$ & $13.55662(126)$ & $359.69(4)$ & $2.818(16)$ & $3.39(2)$ & $0.182(16)$ \\
\hline $1500^{\circ} \mathrm{C}$ & $5.53455(25)$ & $13.55276(108)$ & $359.52(4)$ & $2.804(14)$ & $3.44(2)$ & $0.196(14)$ \\
\hline
\end{tabular}

Table 2. The crystal structure parameters of $\mathrm{La}_{0.6} \mathrm{Sr}_{0.4} \mathrm{FeO}_{3}$ at various quenching temperatures. 


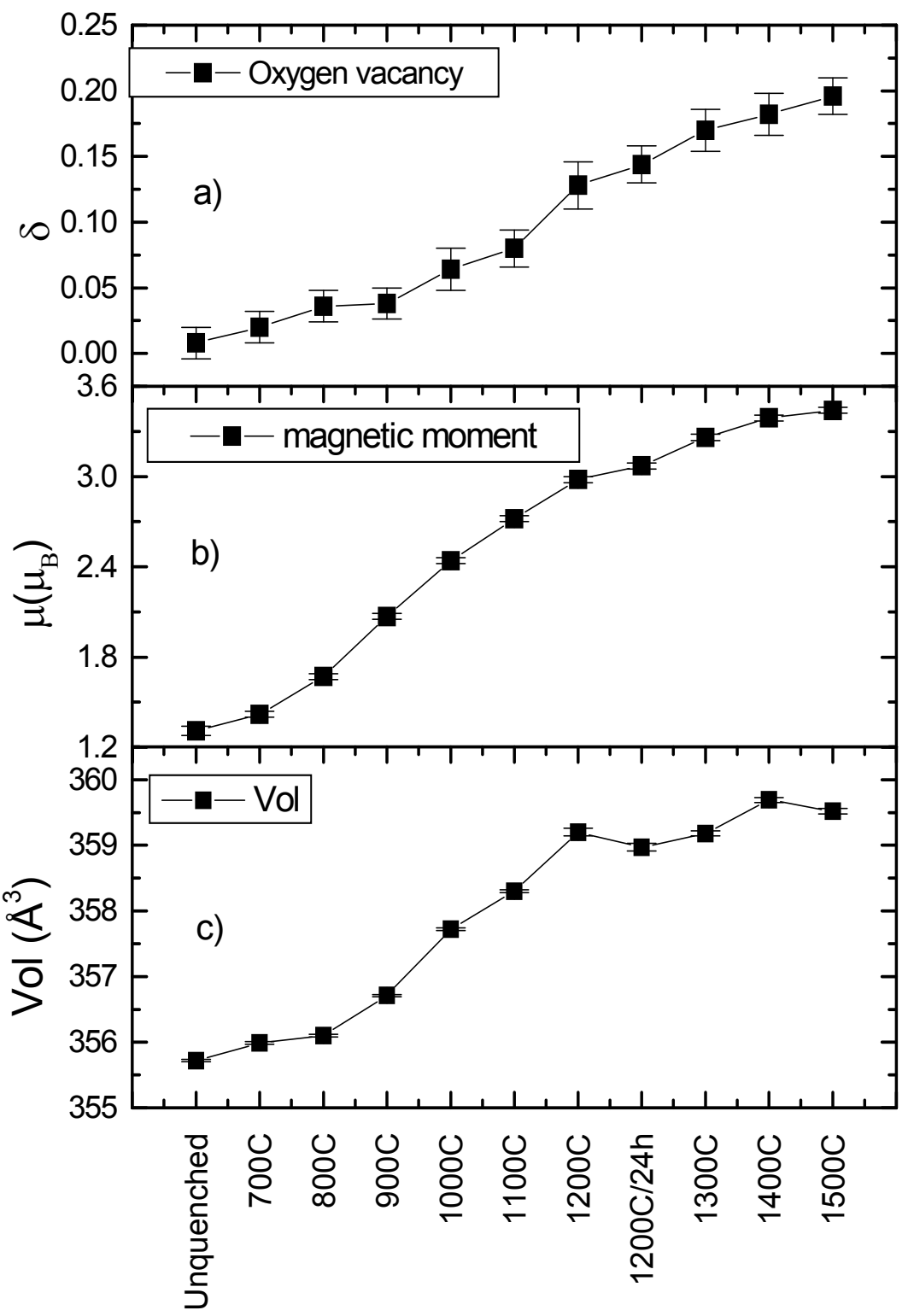

Fig. 8. The changes of oxygen vacancy, magnetic moment, and the unit cell volume with the quench temperature for the $\mathrm{La}_{0.6} \mathrm{Sr}_{0.4} \mathrm{FeO}_{3}$ samples.

Figure 9 shows the magnetic moment and the unit cell volume of L6SF samples as a function of oxygen vacancy concentration. It appears that, in this range, the magnetic moment shows smoother behavior than does the unit cell volume, and may be the more reliable indirect measurement of the oxygen vacancy concentration. 


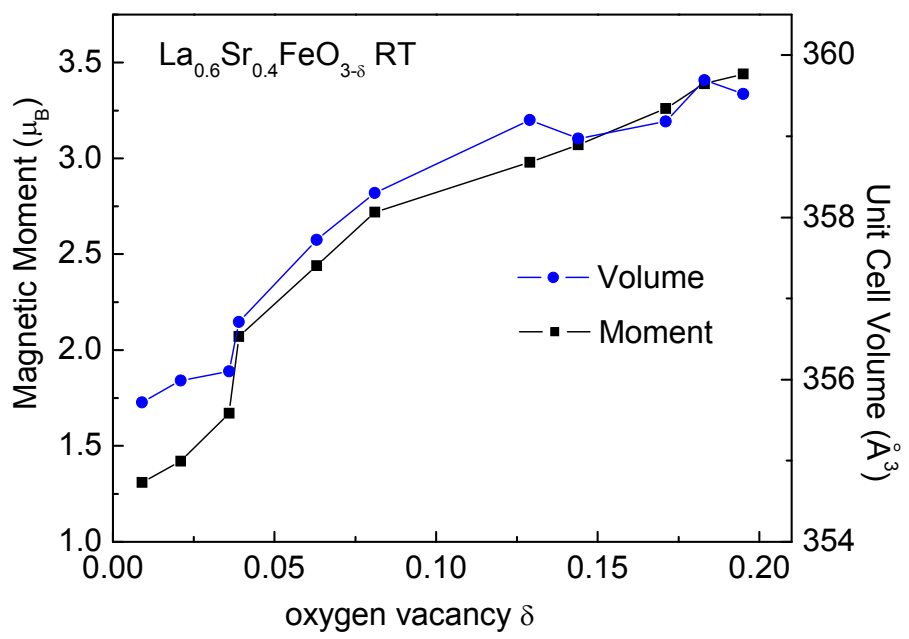

Fig. 9. Magnetic moment and unit cell volume at room temperature vs. oxygen vacancy concentration for $\mathrm{La}_{0.6} \mathrm{Sr}_{0.4} \mathrm{FeO}_{3}$.

The magnetic moment on the Fe sites at room temperature was found to increase from $1.31 \mu_{\mathrm{B}}$ for the untreated sample to $3.44 \mu_{\mathrm{B}}$ for the sample quenched from $1500^{\circ} \mathrm{C}$. The statistical uncertainty in the magnetic moment is less than $2.3 \%$ of the total moment, significantly less than the uncertainty in the vacancy concentration directly determined by the crystallographic refinement. The small increase in moment between the untreated and $700^{\circ} \mathrm{C}$ quenched samples probably reflects the production of a small oxygen vacancy concentration, outside the limit of the direct determination.

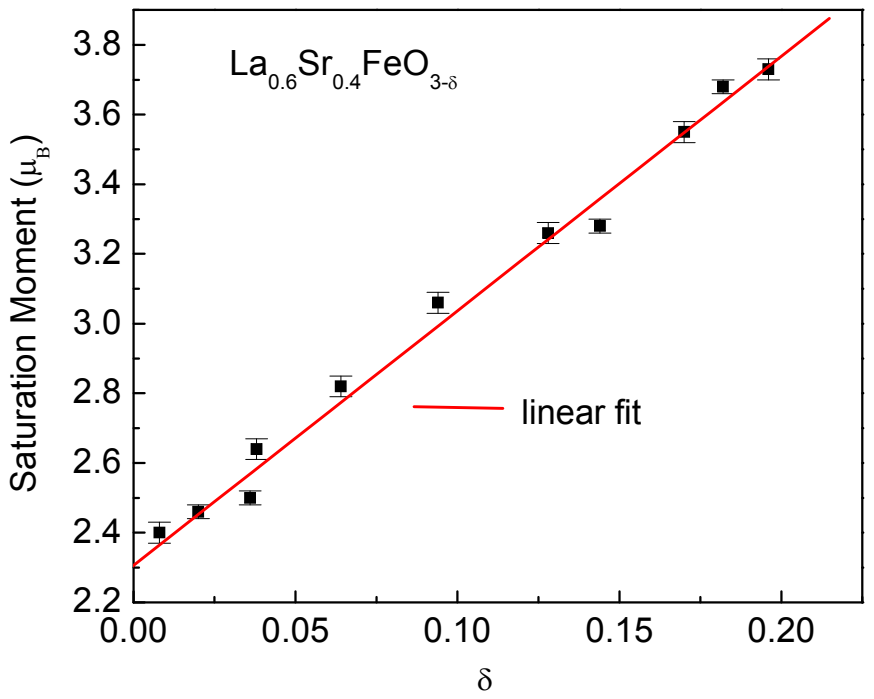

Fig. 10. Oxygen vacancy concentration vs. saturation moment for $\mathrm{La}_{0.6} \mathrm{Sr}_{0.4} \mathrm{FeO}_{3}$ 
Fig. 10 shows the saturation moments, determined from the neutron powder diffraction measurement at $10 \mathrm{~K}$, as a function of oxygen deficiency. The saturation moment is linear with vacancy concentration, the highest deficiency, $\delta=0.2$, corresponds to a nearly pure $\mathrm{Fe}^{3+}$ state, and its magnetic moment is about $3.8 \mu_{\mathrm{B}}$, which is equal to the magnetic moment of $\mathrm{Fe}^{3+}$ in $\mathrm{LaFeO}_{3}$. The moment when $\delta=0$ is about $2.33 \mu_{\mathrm{B}}$, and this value is about $60 \%$ of the magnetic moment of $\mathrm{Fe}^{3+}$. This shows the magnetic moments at Fe sites are contributed by $\mathrm{Fe}^{3+}$, and that the moment of $\mathrm{Fe}^{4+}$ is almost zero. For the ferrites with high $\mathrm{La}$ ( $50 \%$ or more) in an oxidizing environment, it is reasonable to assume that the Fe atoms are in the $3+$ and $4+$ charge states. The great difference between the saturation moments of the two Fe ions provide a direct determination of the ratio of the two ions and, thus, of the oxygen stoichiometry.

The magnetization as a function of temperature follows the Brillouin curve: saturated at low temperature and decreasing slowly up to about $70 \%$ of $T_{N}$ and more rapidly as $T_{N}$ is approached. Thus, according the ratio of the magnetic moment at room temperature to the moment at low temperature (Table 3 ), $\mathrm{T}_{\mathrm{N}}$ is a little above room temperature when the quenching temperature is below $900^{\circ} \mathrm{C}$.

\begin{tabular}{|c|c|c|c|c|c|c|c|c|c|c|}
\hline $\mathrm{T}\left({ }^{\circ} \mathrm{C}\right)$ & $\begin{array}{c}\text { No } \\
\text { Quenching }\end{array}$ & 700 & 800 & 900 & 1000 & 1100 & 1200 & 1300 & 1400 & 1500 \\
\hline $\begin{array}{c}\mu_{\mathrm{RT}} \\
\left(\mu_{\mathrm{B}}\right)\end{array}$ & $1.31(3)$ & $1.42(2)$ & $1.67(2)$ & $2.07(2)$ & $2.44(2)$ & $2.72(2)$ & $2.98(2)$ & $3.26(2)$ & $3.39(2)$ & $3.44(2)$ \\
\hline $\begin{array}{c}\mu_{10 \mathrm{~K}} \\
\left(\mu_{\mathrm{B}}\right)\end{array}$ & $2.40(3)$ & $2.46(2)$ & $2.50(2)$ & $2.64(3)$ & $2.82(3)$ & $3.06(3)$ & $3.26(3)$ & $3.55(3)$ & $3.68(2)$ & $3.73(3)$ \\
\hline$\frac{\mu_{R T}}{\mu_{10 K}}$ & 0.546 & 0.577 & 0.668 & 0.784 & 0.865 & 0.889 & 0.914 & 0.918 & 0.921 & 0.922 \\
\hline $\mathrm{Fe}^{3+\%}$ & 61.4 & 64 & 67.2 & 67.4 & 72.8 & 76 & 85.6 & 94 & 96.4 & 98.4 \\
\hline
\end{tabular}

Table 3. The magnetic moment of $\mathrm{La}_{0.6} \mathrm{Sr}_{0.4} \mathrm{FeO}_{3}$ at different quenching temperature. The $\mathrm{mol} \%$ of $\mathrm{Fe}^{3+}$ is calculated from the oxygen vacancy concentration.

$\mathrm{La}_{0.6} \mathrm{Sr}_{0.4} \mathrm{FeO}_{3}$ exhibits antiferromagnetic ordering below the Neel temperature. Comparing the magnetic moments at room temperature and $10 \mathrm{~K}$, the Neel temperature $\left(\mathrm{T}_{\mathrm{N}}\right)$ increases with increasing oxygen vacancies alone with the concentration of $\mathrm{Fe}^{3+}$. The magnetic interactions between $\mathrm{Fe}$ ions, leading to magnetic ordering in this type of oxide, are predominantly superexchange; exchange that is mediated by polarization of oxygen ions lying between the Fe near neighbors. Since the $\mathrm{Fe}^{4+}$ ions have small or zero moments, the exchange interactions in L6SF are expected to be dominated by the $\mathrm{Fe}^{3+}-\mathrm{O}^{2-}-\mathrm{Fe}^{3+}$ interactions. This is the reason why $\mathrm{T}_{\mathrm{N}}$ increases with increasing $\mathrm{Fe}^{3+}$ concentration, despite the loss of some bonding oxygen atoms.

There are a lot of advantages in using the magnetic moment as a measure of vacancy concentration in $\mathrm{La}_{0.6} \mathrm{Sr}_{0.4} \mathrm{FeO}_{3}$. First, the saturation moment gives an absolute determination without establishing the room temperature curves, while the room temperature moment may be quickly and reliably determined if the correlations have been established. The uncertainty in magnetic moment is $2 \%$ at low vacancy concentration, decreasing to less than $1 \%$ when the moment is large, thus, the vacancy concentration should be known, by this indirect determination, to a precision of $1 \%$ or $2 \%$ over the range of interest. Second, the 
magnetic moment is not affected by the sample position and the model used for the refinement. Third, it is necessary to collect full data sets in order to accurately refine the vacancy concentration, while it is possible to extract the magnetic moment with the low angle range data only, and such data may be collected in as little as 1 hour. Of course, at very high vacancy concentration $(\delta>0.2), \mathrm{Fe}^{2+}$ is expected to appear, with a smaller moment than $\mathrm{Fe}^{3+}$, the average moment at Fe sites will become small as $\delta$ increases, and the linear relationship between the saturation moment and the oxygen vacancy will break down. At those concentrations, however, the direct determination of oxygen vacancy concentration by crystallographic refinement will become more precise.

On the other hand, collection of a full data set allows us to extract all the three determinations: volume, oxygen occupancy, and magnetic moment. These three determinations are essentially independent. The unit cell volume is based only on peak positions and not peak intensities, and uses the full data set. The oxygen occupancies affect the intensities at all angles and especially uses the high angle data, while the magnetic moment is based primarily on the intensities of magnetic peaks at low angle. Thus use of neutron diffraction provides redundancy and cross checks on the oxygen vacancy determination.

\section{Conclusion}

$\mathrm{La}_{0.6} \mathrm{Sr}_{0.4} \mathrm{FeO}_{3}$ shows a very small oxygen vacancy contents prepared by heating in the $\mathrm{N}_{2}$ and $\mathrm{O}_{2}$ gases. When treated in a $\mathrm{CO} / \mathrm{CO}_{2}$ mixture, the amount of oxygen vacancies exceeds $7 \%$. Mössbauer spectra of $\mathrm{N}_{2}$ and $\mathrm{O}_{2}$-quenched samples show a transition from high temperature paramagnetic $\mathrm{Fe}^{3+}$ and $\mathrm{Fe}^{4+}$ valence states to a low temperature antiferromagnetic mixed-valence state resulting from nominal charge disproportionation reaction $2 \mathrm{Fe}^{4+}=\mathrm{Fe}^{3+}+\mathrm{Fe}^{5+}$. The $\mathrm{Fe}$ valence states change from $\mathrm{Fe}^{4+}$ to an intermediate valence state, $\mathrm{Fe}^{(3-\mathrm{x})^{+}}$, in the $\mathrm{CO} / \mathrm{CO}_{2}$-reduced samples. There is no charge disproportionation throughout the entire temperature range. The change of the valence state in the $\mathrm{CO} / \mathrm{CO}_{2}-$ heat treatment increases magnetic moments and the hyperfine fields of the Fe atoms in these compounds. It is found that the antiferromagnetic structure exhibits a small ferromagnetic component, which causes from canted magnetic sublattices $\mathrm{La}_{0.6} \mathrm{Sr}_{0.4} \mathrm{FeO}_{3}$ spacimens quenched from $700-1500^{\circ} \mathrm{C}$ exhibit antiferromagnetic ordering at room temperature, the unit cell volume and the oxygen vacancy concentrations increase with increasing quenching temperature. The magnetic ordering is dominated by the $\mathrm{Fe}^{3+}-\mathrm{O}^{2--} \mathrm{Fe}^{3+}$ interactions, and the $\mathrm{Fe}^{3+}$ concentration increases with increasing oxygen vacancy $\delta$. Thus, the magnetic moment and the Neel temperature increase with increasing oxygen vacancy. The saturation moment, determined by neutron diffraction at $10 \mathrm{~K}$, is linear with the oxygen vacancy $(\delta)$. At high temperature with air flowing, L6SF will absorb oxygen at $303^{\circ} \mathrm{C}-655^{\circ} \mathrm{C}$ and then lose oxygen when temperature is above $655^{\circ} \mathrm{C}$. The presence of oxygen vacancies increases the thermal expansion coefficient.

Neutron diffraction measurement coupled with refinement by the Rietveld method appears to be a reliable, redundant method for determining the oxygen vacancy in L6SF. The unit cell volume, the oxygen occupation, and the magnetic moment can be used to determine the oxygen vacancy. The unit cell volume can be affected by the sample position, but the magnetic moment at room temperature can provide the data more accurately than the other two parameters. The saturation moment $\left(\mu_{10 \mathrm{~K}}\right)$ is an even more powerful tool which can be used to determine the vacancy concentration. 


\section{Acknowledgments}

This work is supported by the National Natural Science Foundation of China (Grant No. 509701003 and 51171001), the National 973 Project (No. 2010CB833104, MOST of China), and the program for New Century Excellent Talents (NCET-10-1097) and the Scientific Research Foundation for Returned Overseas Chinese Scholars, State Education Ministry.

\section{References}

Dann E.; Currie D. B.; Weller M. T.; Thomas M. F.\& Al-Rawwas A. D. (1994) . The Effect of Oxygen Stoichiometry on Phase Relations and Structure in the System $\mathrm{La}_{1-x} \mathrm{Sr}_{x} \mathrm{FeO}_{3-}$ $\delta(0 \leq x \leq 1,0 \leq \delta \leq 0.5)$, J. Solid State Chem. 109, 134-144.

Eror N. G.; \& Anderson H. U.(1986). POLYMERIC PRECURSOR SYNTHESIS OF CERAMIC MATERIALS in "Better ceramics through chemistry II", edited by C J. Briuker, D E. Clark, and D R. Ulrich (Materials Research Society, 1986). Pp571-577. Pittsburgh, PA 1986.

Goodenough J. B. (1955) .Theory of the Role of Covalence in the perovskite-Type Manganites [La,M(II)] $\mathrm{MnO}_{3}$, Phys. Rev., 100, 564-73 .

Kamata K.; Nakajima T.; Hayashi T.; \& Nakamura T. (1978). Nonstoichiometric Behavior and Phase Stability of Rare-Earth Manganites at $1200^{\circ} \mathrm{C}$ : (1). $\mathrm{LaMnO}_{3}$, Mater. Res. Bull., 13, 49-54.

Kuo J. H.; Anderson H. U., \& Sparlin D. M.(1989) . Oxidation-Reduction Behavior of Undoped and Sr-Doped $\mathrm{LaMnO}_{3}$ Nonstoichiometry and defect Structure, J. Solid State Chem., 83, 52-60.

Mizusaki J.; Tagawa H.; Naraya K. \& Sasamoto T. (1991) .Nonstoichiometry and Thermochemical Stability of the perovskite-Type $\mathrm{La}_{1-x} \mathrm{Sr}_{x} \mathrm{MnO}_{3-\delta}$ Solid State Ionics, 49, 111-18.

Patrakeev, M. V.; Bahteeva, J. A.; Mitberg, E. B.; Leonidov, I. A.; Kozhevnikov, V. L. \& Poeppelmeier, K. R. (2003). Electron/hole and ion transport in $\mathrm{La}_{1-x} \mathrm{Sr}_{x} \mathrm{FeO}_{3-\delta}$ Journal of Solid State Chemistry 172, 219-231.

Rodriguez-Carvajal J.(1998), Program: FULLPROF, Version 3.5d. Program for Rietveld Refinement and Pattern Matching Analysis, France.

Srilomsak S.; Schilling D. P. \& Anderson H. U.(1989). Thermal Expansion Studies on Cathode and Interconnect Oxides; pp. 129-40 in Proceedings of the First International Symposium on Solid Oxide Fuel Cells. Edited by S. C. Singhai. The Electrochemical Society, Pennington, NJ, 1989.

Sun, L. \& Brisard, G.(2005), Fuel Cell and Hydrogen Technologies, Proceedings of the International Symposium on Fuel Cell and Hydrogen Technologies, 1st, Calgary, AB, Canada, Aug. 21-24, 85-96. 2005.

Takano, M; Nakanishi N.; Takeda Y.; Naka S., \&Takada T. (1997), Charge disproportionation in $\mathrm{CaFeO}_{3}$ studied with the Mössbauer effect, Mater. Res. Bull. $12,923$.

Yang, J. B.; Yelon, W. B.; James, W. J.; Chu, Z.; Kornecki, M.; Xie, Y. X.; Zhou, X. D.; Anderson, H. U.; Joshi, Amish G.; \& Malik, S. K.;(2002). Crystal structure, magnetic properties, and Mossbauer studies of $\mathrm{La}_{0.6} \mathrm{Sr}_{0.4} \mathrm{FeO}_{3-\delta}$ prepared by quenching in different atmospheres. Physical Review. B 66, 184415-1-184415-9. 


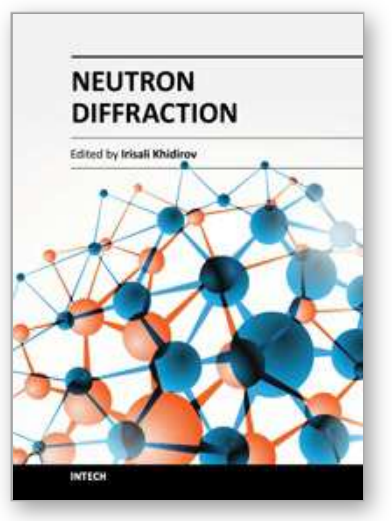

\author{
Neutron Diffraction \\ Edited by Prof. Irisali Khidirov
}

ISBN 978-953-51-0307-3

Hard cover, 286 pages

Publisher InTech

Published online 14, March, 2012

Published in print edition March, 2012

Now neutron diffraction is widely applied for the research of crystal, magnetic structure and internal stress of crystalline materials of various classes, including nanocrystalls. In the present book, we make practically short excursion to modern state of neutron diffraction researches of crystal materials of various classes. The book contains a helpful information on a modern state of neutron diffraction researches of crystals for the broad specialists interested in studying crystals and purposeful regulation of their service characteristics, since the crystal structure, basically, defines their physical and mechanical properties. Some chapters of the book have methodical character that can be useful to scientists, interested in possibilities of neutron diffraction. We hope, that results of last years presented in the book, can be a push to new ideas in studying of crystalline, magnetic structure and a macrostructure of usual crystal materials and nanocrystals. In turn, it can promote working out of new materials with new improved service characteristics and to origin of innovative ideas.

\title{
How to reference
}

In order to correctly reference this scholarly work, feel free to copy and paste the following:

J.B. Yang, Q. Cai, H.L. Du, X.D. Zhou, W.B. Yelon and W.J. James (2012). Neutron Diffraction Studies of the Magnetic Oxide Materials, Neutron Diffraction, Prof. Irisali Khidirov (Ed.), ISBN: 978-953-51-0307-3, InTech, Available from: http://www.intechopen.com/books/neutron-diffraction/neutron-diffraction-studies-of-magneticoxide-materials

\section{INTECH}

open science | open minds

\author{
InTech Europe \\ University Campus STeP Ri \\ Slavka Krautzeka 83/A \\ 51000 Rijeka, Croatia \\ Phone: +385 (51) 770447 \\ Fax: +385 (51) 686166 \\ www.intechopen.com
}

\author{
InTech China \\ Unit 405, Office Block, Hotel Equatorial Shanghai \\ No.65, Yan An Road (West), Shanghai, 200040, China \\ 中国上海市延安西路65号上海国际贵都大饭店办公楼 405 单元 \\ Phone: +86-21-62489820 \\ Fax: $+86-21-62489821$
}


(C) 2012 The Author(s). Licensee IntechOpen. This is an open access article distributed under the terms of the Creative Commons Attribution 3.0 License, which permits unrestricted use, distribution, and reproduction in any medium, provided the original work is properly cited. 